\title{
V2 - ESTUDO VISANDO AUMENTO DO PRAZO DE VALIDADE DA VACINA FEBRE AMARELA 05 E 10 DOSES DE 24 PARA 36 MESES
}

Francis Carazzai Reisdörfer, Paulo César Dick ${ }^{1}$, Izabel Cristina Crespo ${ }^{1}$, Wagner Nascimento Costa ${ }^{1}$, Eliane Coutinho Britto ${ }^{1}$, Darcy Akemi Hokama ${ }^{1}$.

1. Departamento de Controle de Qualidade, Instituto de Tecnologia em Imunobiológicos (Bio-Manguinhos), FIOCRUZ.

Introdução: A vacina febre amarela de Bio-Manguinhos é uma vacina de vírus vivo atenuado, produzida de acordo com as normas da Organização Mundial da Saúde. É utilizada para imunização de adultos e crianças a partir dos 09 meses, principalmente aqueles que transitam em regiões endêmicas. Com o aumento do quantitativo solicitado pelo Ministério da Saúde e para exportação a partir de 2011, inicia-se uma discussão da formação de estoque estratégico desta vacina. Para garantir seu suprimento e melhor aproveitamento de doses distribuídas, evitando o desperdício de uma vacina estável, o aumento do prazo de validade deste produto de 24 para 36 meses é de extrema importância. Assim, Bio-Manguinhos poderia manter um estoque estratégico e ofertar vacina com maior capacidade de uso, suprindo a demanda do Ministério da Saúde, Organização Pan- Americana de Saúde e da Organização Mundial da Saúde, que distribuem esta vacina, respectivamente, para o Brasil, as Américas e a África.

Objetivo : Avaliar a estabilidade da vacina febre amarela (atenuada) 05 doses e 10 doses por 36 meses.

Metodologia: Para a análise da estabilidade da vacina 10 doses, foram avaliados dados retrospectivos e atuais de estudos de estabilidade longa duração e acompanhamento. $\mathrm{O}$ estudo de estabilidade longa duração foi iniciado em 2006 e concluído em 2008, gerando dados de amostras armazenadas por 24 meses a $-20^{\circ} \mathrm{C}$ e a $2-8^{\circ} \mathrm{C}$. Visando à extensão do prazo de validade, as amostras continuaram armazenadas nas mesmas temperaturas por mais 24 meses, totalizando 48 meses, e novos dados foram gerados em 2009 e 2010.

Para a análise da estabilidade da vacina 05 doses, foram avaliados dados retrospectivos de estudos de acompanhamento anual com lotes produzidos em 2003, 2004, 2005 e 2006 e armazenados a $-20^{\circ} \mathrm{C}$ por 36 meses. Além disso, lotes de vacina 05 doses produzidos 
entre 2005 e 2006 e armazenados a $-20^{\circ} \mathrm{C}$ e a $2-8^{\circ} \mathrm{C}$ foram selecionados do arquivo de retenção e avaliados em 2009 e 2010. Para análise estatística foram utilizadas regressão linear e análise de covariância.

Resultados: Os resultados de potência, termoestabilidade e umidade residual mantiveram-se acima do limite especificado durante todo o tempo dos estudos. Os demais parâmetros avaliados também permaneceram dentro das especificações.

A análise estatística mostrou que a potência da vacina 10 doses sofre leve decaimento ao longo do tempo, nas temperaturas de $-20^{\circ} \mathrm{C}$ e $2-8^{\circ} \mathrm{C}$, por 48 meses.

Conclusão: Com esse trabalho, podemos concluir que o prazo de validade das vacinas febre amarela (atenuada) 05 e 10 doses pode ser estendido para 36 meses, quando armazenada a $-20^{\circ} \mathrm{C}$ ou a $2-8^{\circ} \mathrm{C}$, sem alteração da qualida 